\title{
Carcass Composition, Meat Quality, Calpain Activity, Fatty Acid Composition and Ribonucleotide Content in Southern Thai Native Goats and Three-Way Crossbred Goats
}

\author{
Chanporn Chaosap ${ }^{1, *} \mathbb{D}$, Nantana Chauychuwong ${ }^{2}$, Ratchasak Chauychuwong ${ }^{2}$, Chatchai Sriprem ${ }^{2}$, \\ Panneepa Sivapirunthep ${ }^{1}$ and Awis Qurni Sazili ${ }^{3,4}{ }^{(0)}$
}

1 Department of Agricultural Education, Faculty of Industrial Education and Technology, King Mongkut's Institute of Technology Ladkrabang, Bangkok 10520, Thailand; panneepas@yahoo.com

2 Department of Animal Science, Faculty of Agriculture, Rajamangala University of Technology Srivijaya, Nakhon Sri Thammarat 80110, Thailand; nantanachu@yahoo.com (N.C.); rchuychuwong@yahoo.com (R.C.); siam_4403@hotmail.com (C.S.)

3 Department of Animal Science, Faculty of Agriculture, Universiti Putra Malaysia, Serdang 43400, Malaysia; awis@upm.edu.my

4 Institute of Tropical Agriculture and Food Security, Universiti Putra Malaysia, Serdang 43400, Malaysia

* Correspondence: chanporn.ch@kmitl.ac.th; Tel.: +66-838829217

Citation: Chaosap, C.;

Chauychuwong, N.; Chauychuwong,

R.; Sriprem, C.; Sivapirunthep, P.;

Sazili, A.Q. Carcass Composition,

Meat Quality, Calpain Activity, Fatty

Acid Composition and Ribonucleotide

Content in Southern Thai Native Goats and Three-Way Crossbred Goats.

Foods 2021, 10, 1323. https://doi.org/ 10.3390 /foods 10061323

Academic Editors: Pavel Kloucek and Daniel Bures

Received: 11 May 2021

Accepted: 4 June 2021

Published: 8 June 2021

Publisher's Note: MDPI stays neutral with regard to jurisdictional claims in published maps and institutional affiliations.

Copyright: (c) 2021 by the authors. Licensee MDPI, Basel, Switzerland. This article is an open access article distributed under the terms and conditions of the Creative Commons Attribution (CC BY) license (https:// creativecommons.org/licenses/by/ $4.0 /)$.
Abstract: Carcass composition, meat quality, calpain activity, fatty acid composition, and ribonucleotide content were examined and compared between male Southern Thai native goats (NG, $n=10)$ and three-way crossbred goats (CG, 50\% Boer $\times 25 \%$ Saanen $\times 25 \%$ Southern Thai native, $n=10$ ). All animals were fed $1.5 \%$ body weight of concentrate (16\% protein and $70 \%$ total digestible nutrients) and fresh Napier grass for 4 months. At the end of raising period, the final weight between the two genotypes was not significantly different. The percentage of carcass, bone, and fat of CG were higher than those of NG. NG presented lower shear force values, insoluble and total collagen content but higher collagen solubility and calpain- 1 activity at $24 \mathrm{~h}$ postmortem. Additionally, NG meat was high in monounsaturated fatty acids but low in saturated fatty acids. However, the amount of ribonucleotide was no significant difference between two genotypes.

Keywords: collagen; calpain; cholesterol; flavor; fatty acid

\section{Introduction}

Goats are nowadays considered as among the major meat-producing animals as their meat is becoming more acceptable by consumers [1]. The demand for goat meat remarkably increased in Asia and Africa [2] and is also potentially growing in other geographical regions. In Thailand, the goat population continues to grow and has been recorded as one million heads in year 2019 [3]. Most of the goats are owned by smallholder farmers and raised in the southern region of Thailand. Due to the increase in demand, the number of goats raised primarily for meat production grown by $13.67 \%$ in 2019 compared to that in 2018 [3]. The traditional goat production system in Thailand is an extensive grazing system [4]. As the traditional system is insufficient to respond effectively for the growing demand, there is a need for an effectively intensive production system. The improvement of growth performance and feed efficiency in the intensive goat production system is a result of a supplement of concentrates together with using improved meat breeds [5].

The improvement in growth performance and productivity has been accomplished through cross breeding programs by crossing Thai native goats with exotic breeds such as Anglo Nubian, Boer, and Saanen [6]. According to [4], a cross breeding program can improve both carcass and meat quality as three-way crossbreds (50\% Boer $\times 25 \%$ AngloNubian $\times 25 \%$ Southern Thai native) showed significantly higher slaughter weight and carcass weight, larger loin eye area, longer carcass length, and more tender meat than 
two-way crossbreds (50\% Anglo Nubian $\times 50 \%$ Southern Thai native) and Southern Thai native goats, at similar age.

Goat meat is a good source of dietary protein for health-conscious consumers as it contains less fat and cholesterol than traditional meats such as chicken, pork, beef, and lamb [7]. In addition, goat meat is a healthier meat choice as it is low in saturated fatty acids but high in unsaturated fatty acids, which are positively correlated with a reduction of cardiovascular risks [8]. Meat flavor influences goat meat acceptability and palatability. The ribonucleotides such as inosine $5^{\prime}$ monophosphate (IMP) and guanosine $5^{\prime}$ monophosphate (GMP) are major umami substances in meat those can intensify and improve meat flavor [9]. Inosine and hypoxanthine, the degradation products of IMP during the aging period, can potentially affect meat flavor. They do not contribute to umami taste as inosine is a tasteless substance and hypoxanthine produces a bitter taste [10].

Consumers consider the tenderness of meat as one of the most important attributes in meat quality. The considerable amount and crosslinking of collagen-containing connective tissue can significantly affect meat tenderness. As the crosslinks between the molecules of collagen increases with the animal's age, this causes lower solubility of collagen which then results in tougher meat texture. [11]. The other important factor affecting meat tenderness is postmortem proteolysis, and the event mainly involves the endogenous calpain proteolytic system. The $\mathrm{Ca}^{2+}$ dependent calpain proteolytic system consists of calpain-1, calpain-2 and their endogenous protein inhibitor named calpastatin [12]. Postmortem proteolysis of muscle is mainly coming from calpain- 1 and its activity always accompany by its autolysis. The autolysis of calpain-1 during postmortem proteolysis has been used to demonstrate its former activity [13]. The specific protein inhibitor of these enzymes, calpastatin has been reported as the key factor influencing variability in tenderization rate between species (beef $<$ lamb < pork) [14]. Goat meat had higher shear force value and collagen content, so it tended to be tougher than sheep meat [15]. In addition, goat meat tended to have a darker color and lower acceptance compared to lamb [16].

There is scarce scientific information pertaining to the quality characteristics of Thai native goat meat. Additionally, the conducted studies to compare its quality with the improved commercial goat meat breeds are still limited. Therefore, the objectives of this study were to determine and compare carcass composition, meat quality, collagen content, calpain activity, fatty acid composition, and ribonucleotide content between meat obtained from Southern Thai native goats (NG) and three-way crossbred goats (CG) raised under intensive production system.

\section{Materials and Methods}

\subsection{Animal Ethics}

The Animal Care and Use committee of King Mongkut's Institute of Technology Ladkrabang approved all animal procedures in this study (Approval number: ACUCKMITL-RES/2019/010).

\subsection{Experimental Goats and Slaughtering Procedure}

Twenty male goats were selected based on similar initial weight, and the selection was done for Southern Thai native goats (NG, $n=10$ ) and three-way crossbred goats (CG, 50\% Boer $\times 25 \%$ Saanen $\times 25 \%$ Southern Thai native, $n=10$ ). They were fed ad libitum amount of fresh Napier grass and $1.5 \%$ body weight of concentrate that consisted of $16 \%$ protein and $70 \%$ Total Digestible Nutrients (TDN), twice daily. The animals were allowed to access unlimited amount of drinking water, throughout the day. The period of adjustment to the feed was 15 days, following which, the animals were fattened for 4 months. The goats were slaughtered after fattening period and carcass physical composition data were obtained.

\subsection{Muscle Sampling}

Longissimus thoracis (LT) muscles were taken from the left carcasses within $1 \mathrm{~h}$ postmortem. Muscle samples were cut into small pieces, snap-frozen in liquid nitrogen, and 
stored at $\times 80^{\circ} \mathrm{C}$ for further measurement of calpain activity, and ribonucleotide content. The $1.5 \mathrm{~cm}$ thick chop removed from left LT muscle was used to measure drip loss. LT muscles were removed from the right carcasses, measured muscle $\mathrm{pH}$ at $45 \mathrm{~h}$ postmortem, divided into two of 1-inch-thick steaks, and then kept at $1{ }^{\circ} \mathrm{C}$ for $24 \mathrm{~h}$. The first steak was used for $\mathrm{pH}$ and color measurement at $24 \mathrm{~h}$ postmortem then vacuum-packed, continued up to 7 days at $1{ }^{\circ} \mathrm{C}$ and kept at $\times 20^{\circ} \mathrm{C}$ for further cooking loss and shear force measurement. The second steak was vacuum-packed then kept at $\times 20^{\circ} \mathrm{C}$ to further analyze collagen content and fatty acid composition.

\subsection{Meat Characteristics}

\subsection{1. $\mathrm{pH}$ Measurement}

Muscle $\mathrm{pH}$ was directly measured at LT muscle steaks as mentioned in 2.3 using a portable $\mathrm{pH}$ meter equipped with a spear tip glass electrode (SG2-ELK Seven $\mathrm{Go}^{\mathrm{TM}}$, Mettler Toledo International Inc., Giessen, Germany).

\subsubsection{Color Measurement}

The CIE $\mathrm{L}^{*}, \mathrm{a}^{*}$, and $\mathrm{b}^{*}$ value of three measuring positions of the cut surface of 1-inchthick LT steak at $24 \mathrm{~h}$ postmortem as mentioned in 2.3 after $30 \mathrm{~min}$ of blooming at $25 \pm 2{ }^{\circ} \mathrm{C}$ were measured using a hand-held colorimeter with illuminant D65 and $8 \mathrm{~mm}$ of aperture (CR-400 Chromameter, Konica Minolta Sensing Co., Ltd., Tokyo, Japan).

\subsubsection{Drip Loss Measurement}

Each meat sample was individually weighed, hung in a tightly sealed plastic bag, and stored at approximately $1{ }^{\circ} \mathrm{C}$ for $48 \mathrm{~h}$. Meat samples were then cleaned for the excess of superficial juice and reweighed. Drip loss was calculated as a percentage of weight loss before and after suspension.

\subsubsection{Cooking Loss and Shear Force Measurement}

To measure shear force, the frozen 1-inch-thick steak of each LT muscle was thawed and cooked in an $80^{\circ} \mathrm{C}$ water bath until a core temperature of $70^{\circ} \mathrm{C}$ was reached. Cooked meat sample was reweighed after cooling down to room temperature. Cooking loss was expressed as a percentage of weight loss during cooking relative to the original weight. Subsequently, the cooked sample was cut paralleled with the muscle fibers direction into eight slices that were $3 \mathrm{~cm}$ in length and $1 \mathrm{~cm}$ in diameter. The texture analyzer (Model EZ-SX, Shimadzu, Kyoto, Japan) set with a load cell of $50 \mathrm{~kg}$ and a crosshead speed of $50 \mathrm{~mm} / \mathrm{min}$ was used to measure shear force.

\subsection{Fatty Acid Analysis}

The composition of fatty acids (FAs) of LT muscle was determined by gas chromatograph (7890B Agilent, Santa Clara, CA, USA) according to the method previously described [17]. Briefly, the total lipids were extracted from muscle sample by homogenizing with chloroform-methanol $(2: 1, v / v)$ and then evaporating the solvent. The fatty acid methyl esters (FAMEs) were prepared by combing the extracted lipid with $0.5 \mathrm{~N}$ Sodium hydroxide/Methanol and internal standard methyl nonadecanoate (SFA-013N, Accu Standard, New Haven, CT, USA), methylated with $10 \% \mathrm{BF}_{3}$ in methanol, and then analyzed FAs using GC. FAs were identified by comparison of their retention times with those of known standards (F.A.M.E. Mix, C4-C24, Supelco, Bellefonte, PA, USA), and the results was presented as $\mathrm{mg} / 100 \mathrm{~g}$ of fresh muscle.

\subsection{Cholesterol Analysis}

Cholesterol determination was carried out following the method described by [17]. Briefly, the pulverized muscle sample was homogenized in saponification reagent (ethanol: $33 \% \mathrm{KOH}(w / v): 20 \%$ ascorbic acid (94:6:0.5)), mixed with HPLC water and hexane, and allowed the sample to separate into phase for $15 \mathrm{~h}$. The non-saponifiable fraction was care- 
fully collected and evaporated with a stream of nitrogen. After dissolving the dry sample with ethyl acetate, cholesterol content was determined by using gas chromatography (7890B Agilent, Santa Clara, CA, USA) equipped with a Zebron ZB-5 column (Phenomenex, Torrance, CA, USA). The mobile phase consisted of a mixture of acetonitrile and isopropanol $(70: 30, v / v)$ with a $0.5 \mathrm{~mL} / \mathrm{min}$ flow rate. Cholesterol was identified by comparing the retention time of sample peak to that of pure cholesterol standard (Cholesterol C8667, Sigma-Aldrich, Darmstadt, Germany). Cholesterol was quantified by using $5 \alpha$-cholestane as internal standard.

\subsection{Ribonucleotide Analysis}

The content of ribonucleotide, IMP, GMP, inosine, and hypoxanthine was determined according to the method described by [17]. Briefly, $1 \mathrm{~g}$ of pulverized sample was homogenized in $6 \mathrm{~mL}$ of cold $0.6 \mathrm{M}$ perchloric acid, left on ice for $15 \mathrm{~min}$, added $5.4 \mathrm{~mL}$ of $0.8 \mathrm{M}$ $\mathrm{KOH}$ and $0.25 \mathrm{~mL}$ of $\mathrm{KH}_{2} \mathrm{PO}_{4}$ buffer, adjusted $\mathrm{pH}$ to 7.0 with $0.8 \mathrm{M} \mathrm{KOH}$, and made up to the final volume $15 \mathrm{~mL}$ with HPLC water. The mixed sample was centrifuged, and $1 \mathrm{~mL}$ of supernatant was collected to analyze the content of ribonucleotide by using the HPLC (Chromaster, Hitachi, Tokyo, Japan).

\subsection{Collagen Analysis}

The collagen analysis was determined according to the method described by [18]. Briefly, the pulverized meat sample of $0.9 \mathrm{~g}$ was homogenized in five-fold volume of $1 / 4$ strength Ringer's solution $\left(0.86 \% \mathrm{NaCl}, 0.03 \% \mathrm{KCl}\right.$, and $\left.0.033 \% \mathrm{CaCl}_{2}\right)$. The homogenate was heated at $77^{\circ} \mathrm{C}$ for $60 \mathrm{~min}$ in a water bath and then centrifuged at $2500 \times \mathrm{g}$ for $10 \mathrm{~min}$. The supernatant (soluble collagen) and pellet (insoluble collagen) were separated and hydrolyzed for $24 \mathrm{~h}$ at $110{ }^{\circ} \mathrm{C}$ in $12 \mathrm{~N} \mathrm{HCL}$ and $6 n \mathrm{HCl}$, respectively. The cool hydrolysate was added with activated carbon, mixed thoroughly, filtered through a rapid filter paper, adjusted $\mathrm{pH}$ to approximately 6.7 , and diluted the soluble and insoluble fraction with distilled water to either $100 \mathrm{~mL}$ or $500 \mathrm{~mL}$, respectively. The diluted hydrolysate was used to measure hydroxyproline concentration. Collagen content was calculated from the hydroxyproline content by multiplying a conversion factor of 7.25.

\subsection{Casein Zymography}

The activities of calpain- 1 and calpain-2 were analyzed using casein zymography [19]. Briefly, $0.2 \mathrm{~g}$ of pulverized sample was homogenized in $2 \mathrm{~mL}$ of extraction buffer [ $50 \mathrm{mM}$ Tris/ $\mathrm{HCl}$ (pH 7.5), $5 \mathrm{mM}$ EDTA, $200 \mu \mathrm{g} / \mathrm{mL}$ of 4-(2- aminoethyl)-benzenesulphonyl fluoride, $1 \mu \mathrm{g} / \mathrm{mL}$ of leupeptin, $1 \mu \mathrm{g} / \mathrm{mL}$ of pepstatin]. After centrifugation, the supernatant was taken and mixed with an equal volume of loading buffer $[125 \mathrm{mM}$ Tris-HCl pH 6.8, $0.1 \mathrm{M}$ dithiothreitol, $20 \%(v / v)$ glycerol, $0.01 \%(w / v)$ bromophenol blue]. The mixed supernatant was run on native casein acrylamide gel. After electrophoresis, gels were incubated with $\mathrm{Ca}^{2+}$ incubation buffer ( $50 \mathrm{mM}$ Tris-HCl, $\mathrm{pH} 7.0,5 \mathrm{mM} \mathrm{CaCl}_{2}, 10 \mathrm{mM}$ DTT), fixed in in $10 \%(v / v)$ acetic acid, stained with Coomassie blue. Band intensities were quantitated by Quantity One Multi Analyst imaging software (Bio-Rad, Hercules, CA, USA).

\subsection{Statistical Analysis}

Data were expressed as mean \pm standard deviation. Differences were tested by twotailed t-test. Pearson's correlation was used to analyze the association between collagen content, calpain activity, and shear force value parameters. The values $p<0.05$ were considered statistically significant. Statistical analysis was performed using SAS (SAS Institute Inc., Cary, NC, USA).

\section{Results}

NG and CG with similar initial weight were raised in individual cages for four months and fed with fresh Napier grass and $16 \%$ protein concentrate diet at $1.5 \%$ of body weight (Table 1). After the raising period there was no significant difference in the final weight 
between NG and CG ( $p>0.05)$. However, CG had higher carcass dressing percentage $(p<0.05)$, and this could be explained by a tendency for them to present heavier carcass weight $(p=0.072)$. For carcass composition, lean percentage was not significantly different between NG and CG. However, CG had higher percentage of bone and fat than those of NG $(p<0.01)$.

Table 1. Live weight, carcass weight, carcass percentage, carcass length, and carcass composition of Southern Thai native goats (NG) and Three-way crossbred goats (CG).

\begin{tabular}{cccc}
\hline Traits & NG $^{\mathbf{1}}$ & CG $^{\mathbf{1}}$ & $p$-Value \\
\hline Initial weight $(\mathrm{kg})$ & $11.80 \pm 2.18$ & $12.98 \pm 1.22$ & 0.154 \\
Live weight $(\mathrm{kg})$ & $17.33 \pm 2.83$ & $18.12 \pm 1.52$ & 0.446 \\
Carcass $(\mathrm{kg})$ & $7.24 \pm 1.43$ & $8.22 \pm 0.68$ & 0.072 \\
Carcass dressing $(\%)$ & $41.65 \pm 3.00$ & $45.52 \pm 3.91$ & 0.023 \\
Carcass length $(\mathrm{cm})$ & $42.30 \pm 2.31$ & $44.90 \pm 4.68$ & 0.132 \\
Lean $(\mathrm{kg})$ & $5.41 \pm 0.74$ & $5.64 \pm 0.51$ & 0.262 \\
Bone $(\mathrm{kg})$ & $1.32 \pm 0.14$ & $1.57 \pm 0.08$ & 0.0005 \\
Fat $(\mathrm{kg})$ & $0.07 \pm 0.09$ & $0.18 \pm 0.23$ & 0.0002 \\
Lean $(\%)$ & $63.69 \pm 5.68$ & $62.15 \pm 6.54$ & 0.581 \\
Bone $(\%)$ & $16.26 \pm 0.59$ & $18.15 \pm 0.48$ & $<0.0001$ \\
Fat $(\%)$ & $1.00 \pm 0.49$ & $2.22 \pm 0.79$ & 0.0006 \\
\hline
\end{tabular}

${ }^{1}$ Mean \pm SD.

The average muscle $\mathrm{pH}$ was not significantly different between two genotypes (Table 2). Meat color values of NG and CG were not different. The instrumental color values of $\mathrm{L}^{*}$, $\mathrm{a}^{*}$, and $\mathrm{b}^{*}$ in NG and CG meat are 30.01 and 32.77, 13.43 and 13.83, and 13.61 and 14.78, respectively. The average drip loss recorded in the LT muscle from the two genotypes, was $2.07 \%$ and $1.93 \%$, for NG and CG, respectively. The percentage of cooking loss was not significantly different between two genotypes. Shear force value of NG was significantly lower than that from CG $(p<0.01)$.

Table 2. Meat quality characteristics in Longissimus thoracis m. of Southern Thai native goats (NG) and Three-way crossbred goats (CG).

\begin{tabular}{cccc}
\hline Traits & NG $^{\mathbf{1}}$ & CG $^{\mathbf{1}}$ & $p$-Value \\
\hline $\mathrm{pH}_{45}$ & $6.46 \pm 0.36$ & $6.55 \pm 0.28$ & 0.520 \\
$\mathrm{pH}_{24}$ & $5.97 \pm 0.45$ & $5.74 \pm 0.13$ & 0.150 \\
$\mathrm{~L}^{*}$ & $30.01 \pm 3.03$ & $32.77 \pm 5.10$ & 0.160 \\
$\mathrm{a}^{*}$ & $13.43 \pm 1.77$ & $13.83 \pm 2.99$ & 0.725 \\
$\mathrm{~b}^{*}$ & $13.62 \pm 1.69$ & $14.78 \pm 2.69$ & 0.261 \\
Drip loss $(\%)$ & $2.07 \pm 0.38$ & $1.93 \pm 0.24$ & 0.350 \\
Cooking loss $(\%)$ & $29.03 \pm 2.64$ & $27.29 \pm 3.20$ & 0.202 \\
Shear force $(n)$ & $32.80 \pm 2.80$ & $46.30 \pm 4.90$ & $<0.0001$ \\
\hline
\end{tabular}

${ }^{1}$ Mean \pm SD.

NG had lower amount of insoluble collagen and total collagen content $(p<0.05)$ and higher percentage of collagen solubility $(p<0.01$, Table 3$)$. The non-denaturing casein zymography was used to measure calpain activity in this study. There was no significant difference in calpain- 1 activity at $1 \mathrm{~h}$ postmortem $(p>0.05)$ between the two genotypes, while NG showed higher activity of calpain- 1 at $24 \mathrm{~h}$ postmortem $(p<0.05)$ than that in their counterpart. However, the activity of calpain-2 was not different between the two genotypes $(p>0.05)$. During $24 \mathrm{~h}$ postmortem, calpain- 1 activity decreased approximately $91 \%$ and $92 \%$, while calpain- 2 activity decreased $45 \%$ and $43 \%$ for NG and CG, respectively. The higher decreasing percentage of calpain- 1 activity during $24 \mathrm{~h}$ postmortem imply greater response of calpain- 1 than calpain- 2 on postmortem proteolysis. 
Table 3. Collagen content and calpain activity in Longissimus thoracis $\mathrm{m}$. of Southern Thai native goats (NG) and Three-way crossbred goats (CG).

\begin{tabular}{|c|c|c|c|}
\hline Traits & $\mathrm{NG}^{1}$ & $\mathrm{CG}^{1}$ & $p$-Value \\
\hline \multicolumn{4}{|l|}{ Collagen content $^{2}$} \\
\hline Soluble collagen & $0.11 \pm 0.04$ & $0.09 \pm 0.03$ & 0.211 \\
\hline Insoluble collagen & $3.02 \pm 0.51$ & $3.67 \pm 0.71$ & 0.010 \\
\hline Total collagen & $3.50 \pm 0.52$ & $4.28 \pm 0.75$ & 0.015 \\
\hline Collagen solubility (\%) ${ }^{3}$ & $3.18 \pm 0.98$ & $2.10 \pm 0.53$ & 0.006 \\
\hline \multicolumn{4}{|l|}{ Calpain activity 4} \\
\hline Calpain- $1_{1 \mathrm{~h}}$ & $1.88 \pm 0.14$ & $1.74 \pm 0.36$ & 0.247 \\
\hline Calpain- $1_{24 \mathrm{~h}}$ & $0.18 \pm 0.02$ & $0.14 \pm 0.04$ & 0.017 \\
\hline Calpain- $21 \mathrm{~h}$ & $1.61 \pm 0.18$ & $1.58 \pm 0.30$ & 0.799 \\
\hline Calpain-2 $24 \mathrm{~h}$ & $0.87 \pm 0.09$ & $0.88 \pm 0.16$ & 0.994 \\
\hline
\end{tabular}

Pearson's correlation coefficients between collagen content, calpain activity and shear force value of LT muscle of Southern Thai native goats and three-way crossbred goats are shown in Table 4. Shear force values were not correlated with soluble collagen content and $\%$ collagen solubility, while insoluble collagen $(\mathrm{r}=0.40, p=0.080)$ and total collagen content $(\mathrm{r}=0.46, p=0.047)$ were positively correlated with the shear force values. Calpain- 1 activity at $1 \mathrm{~h}$ postmortem was not correlated $(p>0.05)$, but calpain- 1 activity at $24 \mathrm{~h}$ postmortem was negatively correlated with shear force values $(\mathrm{r}=-0.65, p=0.002)$. The activity of calpain-2 at $1 \mathrm{~h}$ and $24 \mathrm{~h}$ postmortem was not correlated with shear force $(p>0.05)$.

Table 4. Pearson's correlation coefficients between collagen content, calpain activity, and shear force value of Longissimus thoracis $\mathrm{m}$. of Southern Thai native goats and Three-way crossbred goats.

\begin{tabular}{ccc}
\hline Trait & Pearson's Correlation Coefficient & $p$-Value \\
\hline Collagen content & & \\
Soluble collagen & -0.003 & 0.991 \\
Insoluble collagen & 0.401 & 0.080 \\
Total collagen & 0.461 & 0.047 \\
Collagen solubility (\%) & -0.216 & 0.373 \\
Calpain activity & & \\
Calpain-1 1 h & -0.208 & 0.379 \\
Calpain-1 24 h & -0.650 & 0.002 \\
Calpain-2 1 h & -0.082 & 0.731 \\
Calpain-2 $24 \mathrm{~h}$ & -0.060 & 0.801 \\
\hline
\end{tabular}

The content of total cholesterol was recorded as $72 \mathrm{mg} / 100 \mathrm{~g}$ and $80 \mathrm{mg} / 100 \mathrm{~g}$ in NG and CG, respectively, and did not differ between the two genotypes when animals were slaughtered at similar slaughter weight (Table 5). The main individual fatty acids found in the LT muscle of the two genotypes are oleic, palmitic, and stearic acids (Table 5). NG had a significantly higher amount of unsaturated oleic acid $(p=007)$ but a lower amount of saturated myristic acid $(p=0.037)$, palmitic $(p=0.027)$, behenic acid $(p=0.011)$, and stearic acid $(p=0.074)$ leading to higher MUFA $(p=0.005)$ and lower SFA $(p=0.001)$ in NG than those in CG. However, only saturated heneicosylic acid was observed at significantly higher concentration in NG than that in CG $(p<0.05)$. The considerably lower level of saturated palmitic acid and stearic acid in native purebred goats compared to crossbred goats. The desirable fatty acids (DFA), the PUFA/SFA ratio and the ratio of $n-6 / n-3$ were not affected by goat genotypes $(p>0.05)$. 
Table 5. Cholesterol content and fatty acid composition in Longissimus thoracis $\mathrm{m}$. of Southern Thai native goats (NG) and Three-way crossbred goats (CG).

\begin{tabular}{|c|c|c|c|c|}
\hline Traits & & $\mathrm{NG}^{1}$ & $\mathrm{CG}^{1}$ & $p$-Value \\
\hline $\begin{array}{c}\text { Cholesterol }^{2} \\
\text { Fatty acid } \\
\text { composition }^{3}\end{array}$ & & $71.88 \pm 15.15$ & $79.99 \pm 11.38$ & 0.178 \\
\hline Myristic acid & C14:0 & $1.63 \pm 0.18$ & $2.29 \pm 0.65$ & 0.037 \\
\hline Pentadecanoic acid & C15:0 & $2.32 \pm 0.38$ & $3.08 \pm 1.01$ & 0.143 \\
\hline Palmitic acid & $\mathrm{C} 16: 0$ & $17.89 \pm 1.10$ & $20.08 \pm 1.64$ & 0.027 \\
\hline Palmitoleic acid & C16:1 & $1.80 \pm 0.43$ & $1.80 \pm 0.44$ & 0.989 \\
\hline Margaric acid & C17:0 & $13.86 \pm 2.11$ & $12.34 \pm 2.17$ & 0.253 \\
\hline Heptadecenoic acid & $\mathrm{C} 17: 1$ & $1.24 \pm 0.14$ & $1.08 \pm 0.18$ & 0.114 \\
\hline Stearic acid & C18:0 & $12.63 \pm 1.33$ & $14.32 \pm 1.53$ & 0.074 \\
\hline Elaidic acid & $\mathrm{C} 18: \ln 9 \mathrm{t}$ & $0.76 \pm 0.07$ & $0.81 \pm 0.18$ & 0.602 \\
\hline Oleic acid & $\mathrm{C} 18: \ln 9 \mathrm{c}$ & $37.00 \pm 1.99$ & $30.61 \pm 3.84$ & 0.007 \\
\hline Linoleic acid & $\mathrm{C} 18: 2 \mathrm{n} 6 \mathrm{c}$ & $3.72 \pm 0.91$ & $4.67 \pm 1.44$ & 0.229 \\
\hline$\alpha$-Linolenic acid & C18:3n3 & $0.51 \pm 0.09$ & $0.44 \pm 0.14$ & 0.344 \\
\hline Heneicosylic acid & $\mathrm{C} 21: 0$ & $0.46 \pm 0.06$ & $0.36 \pm 0.07$ & 0.036 \\
\hline Behenic acid & $\mathrm{C} 22: 0$ & $0.60 \pm 0.27$ & $1.20 \pm 0.36$ & 0.011 \\
\hline Tricosylic acid & C23:0 & $4.36 \pm 1.17$ & $5.04 \pm 1.98$ & 0.512 \\
\hline Eicosapentaenoic acid & C20:5n3 & $1.22 \pm 0.49$ & $1.88 \pm 0.98$ & 0.195 \\
\hline SFA & & $53.76 \pm 1.93$ & $58.73 \pm 1.91$ & 0.001 \\
\hline MUFA & & $40.80 \pm 2.20$ & $34.29 \pm 3.62$ & 0.005 \\
\hline PUFA & & $5.44 \pm 1.36$ & $6.98 \pm 2.39$ & 0.226 \\
\hline DFA & & $58.87 \pm 1.02$ & $55.60 \pm 2.42$ & 0.114 \\
\hline PUFA: SFA & & $0.10 \pm 0.03$ & $0.12 \pm 0.04$ & 0.423 \\
\hline$\omega-6$ & & $3.72 \pm 0.91$ & $4.66 \pm 1.44$ & 0.229 \\
\hline$\omega-3$ & & $1.72 \pm 0.56$ & $2.32 \pm 1.07$ & 0.283 \\
\hline$\omega-6: \omega-3$ & & $2.24 \pm 0.49$ & $2.32 \pm 1.04$ & 0.889 \\
\hline
\end{tabular}

${ }^{1}$ Mean \pm SD. ${ }^{2} \mathrm{mg} / 100 \mathrm{~g} .{ }^{3} \mathrm{~g} / 100 \mathrm{~g}$ of total fatty acids. SFA (saturated fatty acids): C14:0+C15:0+C16:0+C17:0+ C18:0+C21:0+C22:0+C23:0; MUFA (monounsaturated fatty acids): C16:1 + C17:1 + C18:1n9t + C18:1n9c; PUFA (polyunsaturated fatty acids): C18:2n6c + C18:3n3 + C20:5n3;.DFA (desirable fatty acids): MUFA + PUFA + C18:0 $\omega-6:$ C18:2n6c; $\omega-3:$ C18:3n3+C20:5n3.

There was no significant effect of goat genotypes on ribonucleotide content as the amount of IMP, GMP, and inosine did not differ $(p>0.05)$ between NG and CG, with a tendency for the amount of hypoxanthine to be higher in muscles of NG than those of CG $(p<0.1$, Table 6).

Table 6. The ribonucleotides content in Longissimus thoracis m. of Southern Thai native goats (NG) and Three-way crossbred goats (CG).

\begin{tabular}{cccc}
\hline Ribonucleotide Content $^{\mathbf{1}}$ & $\mathbf{N G}^{\mathbf{2}}$ & $\mathbf{C G}^{\mathbf{2}}$ & $\boldsymbol{p}$-Value \\
\hline Hypoxanthine & $0.74 \pm 0.28$ & $0.52 \pm 0.12$ & 0.091 \\
Inosine & $5.44 \pm 1.35$ & $5.49 \pm 2.21$ & 0.959 \\
Inosine monophosphate & $25.61 \pm 4.67$ & $28.91 \pm 6.58$ & 0.328 \\
Guanosine monophosphate & $0.82 \pm 0.19$ & $0.88 \pm 0.29$ & 0.682 \\
\hline
\end{tabular}

${ }^{1} \mathrm{mg} / 100$ g. ${ }^{2}$ Mean \pm SD.

\section{Discussion}

In the present study, the initial weight and final weight of NG and CG were the same, but CG had higher percentage of carcass, bone, and fat than those in NG. However, the lean percentage was not significantly different between two genotypes. According to [6], Southern Thai native goats presented lower body weight at the same age compared to three-way crossbred goats $(50 \%$ Boer $\times 25 \%$ Anglo-Nubian $\times 25 \%$ Southern Thai native), which were 1.79 and $3.32 \mathrm{~kg}$ at birth, 8.10 and $16.02 \mathrm{~kg}$ at 3 months old, 12.22 and $25.68 \mathrm{~kg}$ at 6 months old, and 16.43 and $34.14 \mathrm{~kg}$ at 9 months old, respectively. From the study of [4], male yearlings of three-way crossbred goats $(50 \%$ Boer $\times 25 \%$ Anglo- 
Nubian $\times 25 \%$ Southern Thai native) had heavier slaughter weight ( 37.50 vs. $18.35 \mathrm{~kg})$ and hot carcass weights (19.08 vs. $8.75 \mathrm{~kg}$ ) and longer carcass length (66.58 vs. $48.42 \mathrm{~cm})$ compared to Southern Thai native goats $(p<0.01)$. However, they reported that hot carcass dressing percentage was not significantly different, between both genotypes, as $48.10 \%$ vs. $47.49 \%$, respectively. In contrast, our study found lower hot carcass dressing percentage in NG compared to those of CG at similar slaughter weight with different slaughter age at approximately 9 months old and 6 months old for NG and CG, respectively. The study shows that there was no significant difference on lean percentage between the two genotypes. While NG had lower fat and bone percentage. Anothaisinthawee et al. [4] reported higher bone percentage without any differences in lean or fat percentage between Southern native goat and three-way crossbred goats. Khaokhaikaew et al. [20] also reported higher bone percentage in Anglo-Nubian $\times$ Thai native goats with no differences in lean and fat percentages when compared with those of native goats.

The rate and extent of postmortem $\mathrm{pH}$ decline has a significant effect on meat quality traits especially to meat color, water holding capacity, and tenderness [21]. In this study, the average muscle $\mathrm{pH}$ from both genotypes gradually fell from $\sim 6.5$ to $\sim 5.8$, over $24 \mathrm{~h}$ postmortem (Table 2). The high ultimate $\mathrm{pH}$ value in this study records that both NG and CG at 5.97 and 5.74, respectively, is aligned with results from several studies [22-24]. A possibility is what [15] and [25] refer to as goats are generally highly prone to stress and the high ultimate $\mathrm{pH}$ value is the consequence of preslaughter stress.

The most important quality attribute that influences consumers' purchasing decision is the color of meat [26]. The usual preference of meat color is bright red meat. Goat meat normally has a darker shade than other red meats [24]. There was no effect of genotype on meat color in this study. The instrumental color values of $\mathrm{L}^{*}, \mathrm{a}^{*}$, and $\mathrm{b}^{*}$ in both groups were in the range from 30.01 to $32.77,13.43$ to 13.83 , and 13.61 to 14.78 , respectively. The present results of color values are consistent with those reported in several goat breeds [23,27].

No significant differences in drip loss percentage found in this study was in agreement with [28], who found no significant difference in drip loss percentage between Lat goats and their crossbreds, as $1.31 \%$ and $0.93 \%$, respectively. The percentage of cooking loss recorded in the current study falls within the normal range of $27-29 \%$ for goat muscles $[4,22,24]$. Generally, genotypes did not affect water holding capacity, and this was indicated by no significant differences in drip loss and cooking loss percentages between NG and CG. Other studies have not reported that breed affects water holding capacity [22] and cooking loss [4]. Water holding capacity related parameters have been related to the ultimate $\mathrm{pH}$ of meat [29]. Therefore, the possible explanation for the similarity of drip loss and cooking loss observed between NG and CG could be explained by the similarity in their ultimate meat $\mathrm{pH}$ values.

Meat tenderness is one of the most important quality traits in consumers' perception to quality of meat. When shear force value of meat is less than $5.5 \mathrm{~kg}$, it can be considered as tender meat [30]. In this study, LT muscles of NG demonstrated lower shear force values than that of CG. However, [4] reported higher shear force values in native goats compared to the three-way crossbred goats. The variation in shear force values between two studies may be attributed to the differences in nutrition, slaughter weight, and age of goats.

The major protein in connective tissue is collagen [31]. The quantity and heat solubility of collagen significantly impact meat tenderness [32]. Tender meat has low collagen content and high collagen solubility [11]. In this study, NG had lower amount of insoluble collagen and total collagen content $(p<0.05)$ and higher percentage of collagen solubility $(p<0.01$, Table 3). The total collagen content in this study is within the range of $2-6 \mathrm{mg} / \mathrm{g}$, which has been shown in previous studies [33,34].

In this study, the non-denaturing casein zymography was used to measure calpain activity. There was no significant difference in calpain-1 activity at $1 \mathrm{~h}$ postmortem $(p>0.05)$ between the two genotypes, while NG showed higher activity of calpain-1 at $24 \mathrm{~h}$ postmortem $(p<0.05)$ than that in their counterpart. However, the activity of calpain- 2 was not different between the two genotypes $(p>0.05)$. During $24 \mathrm{~h}$ postmortem, calpain-1 
activity decreased approximately $91 \%$ and $92 \%$, while calpain- 2 activity decreased $45 \%$ and $43 \%$ for NG and CG, respectively. The higher decreasing percentage of calpain-1 activity during $24 \mathrm{~h}$ postmortem imply greater response of calpain-1 than calpain-2 on postmortem proteolysis. Similarly, [35] reported higher decrease of calpain-1 activity than calpain-2 activity in goat muscle during postmortem storage. Data generated from studies in goats are still limited and thus, the information from other ruminant species such as beef cattle have been used to demonstrate breed effect on the calpain system. A study documented by [36] demonstrated breed effects on the calpain- 1 and calpastatin activities. They reported that calpain- 1 activity decreased as Brahman percentage increased, and higher calpain-1 activity in 0\% Brahman steers than 100\% Brahman steers. In addition, earlier, [37] noted that the higher level of calpastatin activity responded for the lower meat tenderness of Brahman purebred compared to Bos taurus crossbred.

In this study, the meat of NG was generally more tender than CG meat as it had lower shear force values. The lower amount of collagen content, higher percentage of collagen solubility, and higher activity of calpain- 1 at $24 \mathrm{~h}$ postmortem could be responsible for greater postmortem tenderization in NG meat than that in CG meat. As expected, there was a positive correlation between shear force and total collagen content and a negative correlation between shear force and calpain- 1 activity at $24 \mathrm{~h}$ postmortem observed in this study. In agreement with [38] as they reported a positive correlation between shear force and collagen content. The negative relationship between shear force and calpain-1 activity found in this study could be supported by calpain system, especially calpain-1 is responsible for postmortem proteolysis during ageing process resulting in meat tenderization [12-14].

The content of total cholesterol was recorded as $72 \mathrm{mg} / 100 \mathrm{~g}$ and $80 \mathrm{mg} / 100 \mathrm{~g}$ in NG and CG, respectively and did not differ between the two genotypes when animals were slaughtered at similar slaughter weight (Table 5). Similarly, [39] reported no genotype effect on cholesterol content. According to these authors, cholesterol values lower than those found in this study, the cholesterol levels from in LT muscle of local Argentina goat and Anglo-Nubian goat ranged from $60-66 \mathrm{mg} / 100 \mathrm{~g}$. Pratiwi et al. [40] also reported low cholesterol content in LT muscle of castrated Boer goats slaughtered with different ages and weights ranged from $55-60 \mathrm{mg} / 100 \mathrm{~g}$. However, the values of cholesterol found in this study can be considered moderate as it is lower than $90 \mathrm{mg} / 100 \mathrm{~g}$ [40].

In this study, the main individual fatty acids found in both NG and CG meat are oleic, palmitic, and stearic acids, and this is in agreement with [41,42]. Genotype affected the proportion of the individual fatty acids in this study, consistent with [42] who found lower amount of palmitic acid in Boer than in Australian feral bucks. The considerably lower level of saturated palmitic acid and stearic acid in native purebred goats compared to crossbred goats in this study contradict those reported by [41], that the greater amount of palmitic and stearic acid was recorded in Argentinean native goats than those in their crossbreds.

From a nutritional point of view, NG goats exhibited better nutritional quality according to their meat had higher MUFA and lower SFA compared to CG. Abdullah et al. [43] reported the beneficial health effects of MUFA-rich diets regarding to the improvements of the incidence of coronary heart disease and type 2 diabetes along with the potential economic benefits from healthcare cost savings. The beneficial effects of fatty acids to meat consumers' needs can be also considered from many aspects such as the DFA, the PUFA/SFA ratio, and the ratio of $\omega-6: \omega-3$. The DFA consist of C18:0 and all unsaturated fatty acids and should be of high levels in healthy meat [44].

In general, the PUFA/SFA ratio above 0.45 has been recommended in human diet as a way to prevent coronary heart disease [45]. Within PUFA, $n-3$ PUFA content should be higher than $n-6$ PUFA content since the undesirably higher content of $n-6$ PUFA has been associated with higher incidence of coronary diseases [46]. Earlier, the acceptable value for the $n-6 / n-3$ ratio was reported as less than 5 [47]. In the current study, the DFA in muscles of NG was slightly higher than those in CG and was recorded as $58.9 \mathrm{~g} / 100 \mathrm{~g}$ and $55.6 \mathrm{~g} / 100 \mathrm{~g}$ of total fatty acids, respectively. There were no significant differences 
in PUFA/SFA ratio and $n-6 / n-3$ ratio between the two genotypes. The PUFA/SFA ratio in muscles of both genotypes ranged between 0.10 and 0.12 . The PUFA/SFA ratio recorded by [40] is 0.20 for Australian feral goats at $20 \mathrm{~kg}$ slaughter weight. The $n-6 / n-3$ was comparable to that documented by [39] in Argentinean native Criollo Cordobes goats but was lower than the ratio in Anglo-Nubian goats which are 2.58 and 2.89, and 3.69 and 4.04 at 10 and $11 \mathrm{~kg}$ slaughter weight, respectively.

It is well accepted that consumer satisfaction on meat and meat products are highly influenced by tenderness, juiciness, and flavor. Flavor appears to be one of the most important sensory properties in determining consumer acceptability of meat [48]. The ribonucleotides, mainly IMP and GMP contribute to the umami taste in meat and meat products [9]. IMP has been considered as the key index of meat flavor as it is a main component of the flavor of meat [49]. It has been well accepted that ATP in muscle decreases rapidly after animal death, leading to muscle stiffening known as rigor mortis, which is related to a large amount of IMP accumulation [50]. The breakdown products of IMP during postmortem storage, inosine, and hypoxanthine could also impact meat flavor as they have been reported to have either a bitter or tasteless taste $[10,51]$. The insignificant effect of genotype on ribonucleotide content in this study implies that the flavor intensity of meat from NG and CG were almost the same.

Generally, it has been well established that cross breeding program can improve growth performance and productivity. The improvement of productivity was manifested in this study as higher carcass percentage in three-way crossbred goats compared to native goats. However, the native goats had better meat quality compared to the crossbreds and this is not in agreement with the previous study [4]. The inconsistent findings between studies may be explained by the differences in breed, age and diet, and environmental factors such as climate, weather, husbandry, and management systems.

\section{Conclusions}

Southern Thai native goats demonstrated more tender, higher MUFA, and lower SFA meat. The more tender meat produced by the Southern Thai native could be explained by lower total collagen and insoluble collagen contents, higher percentage of collagen solubility, and higher activity of calpain-1 at $24 \mathrm{~h}$ postmortem. The higher carcass dressing percentage shown by the CG group could be due to the higher fat and bone composition. However, despite being larger in terms of carcass weight and dressing percentage, the amount of lean which is economically referred as saleable meat was similar between NG and CG.

Author Contributions: Conceptualization, Methodology, Resources, Formal analysis, Visualization, Writing-original draft, Writing - review and editing, C.C.; Project administration, Visualization, Supervision, N.C. and R.C.; Visualization, Writing—original draft, Writing—review and editing, P.S. and A.Q.S.; Investigation, Methodology, Resources, C.S. All authors have read and agreed to the published version of the manuscript.

Funding: This research was funded by National Research Council of Thailand Not applicable, grant number 2559A17102121.

Institutional Review Board Statement: The experiment was approved by the Animal Care and Use committee of King Mongkut's Institute of Technology Ladkrabang (Approval number: ACUCKMITL-RES/2019/010).

Informed Consent Statement: Not applicable.

Data Availability Statement: The data presented in this study are available on request from the corresponding author.

Conflicts of Interest: The authors declare no conflict of interest. 


\section{References}

1. Devendra, C. Dynamics of goat meat production in extensive systems in Asia: Improvement of productivity and transformation of livelihoods. Agrotechnoly 2015, 4, 131.

2. Food and Agriculture Organization of the United Nation. Agricultural Data. Available online: http://www.fao.org/faostat/en/ \#data/QC (accessed on 1 December 2019).

3. Information Technology Center. National Animal Statistics; Department of Livestock Development: Bangkok, Thailand, 2019.

4. Anothaisinthawee, S.; Wattanachant, C.; Nomura, K.; Oishi, T.; Amano, T. Carcass and meat quality of three genotype population in goat breeding for meat purposes in Thailand. J. Agric. Sci. Tokyo Univ. Agric. 2012, 57, 63-70.

5. Seré, C.; Steinfeld, H.; Groenewold, J. World livestock production systems: Current status, issues and trends. In Proceedings of the a Consultation on Global Agenda for Livestock Research, Nairobi, Kenya, 18-20 January 1995; ILRI: Nairobi, Kenya, 1995.

6. Anothaisinthawee, S.; Nomura, K.; Oishi, T.; Amano, T. Goat genetic resources and breeding strategies in Thailand. J. Anim. Genet. 2010, 38, 41-48. [CrossRef]

7. USDA. USDA Nutrient Database for Standard Reference, Release 14, Nutrient Data Laboratory. 2002. Available online: http:/ / www.nal.usda.gov/fnic/foodcomp (accessed on 1 December 2019).

8. Madruga, M.; Resosemito, F.; Narain, N.; Souza, W.; Cunha, M.; Ramos, J. Effect of raising conditions of goats on physico-chemical quality of its meat. CYTA J. Food 2006, 5, 100-104.

9. Dunford, E.; Shahidi, F. Flavour of fish meat. In Flavor of Meat, Meat Products and Seafoods, 2nd ed.; Shahidi, F., Ed.; Blackie Academic and Professional: London, UK, 1998; pp. 131-158.

10. Jones, N.R. Meat and fish flavors; significance of ribomononucleotides and their metabolites. J. Agric. Food Chem. 1969, 17, 712-716. [CrossRef]

11. Lawrie, R. Meat Science; Pergamon Press: Oxford, UK, 1998.

12. Goll, D.E.; Thompson, V.F.; Li, H.; Wei, W.; Cong, J. The Calpain System. Physiol. Rev. 2003, 83, 731-801. [CrossRef] [PubMed]

13. Geesink, G.H.; Kuchay, S.; Chishti, A.H.; Koohmaraie, M. $\mu$-Calpain is essential for postmortem proteolysis of muscle proteins1,2. J. Anim. Sci. 2006, 84, 2834-2840. [CrossRef] [PubMed]

14. Koohmaraie, M.; Geesink, G. Contribution of postmortem muscle biochemistry to the delivery of consistent meat quality with particular focus on the calpain system. Meat Sci. 2006, 74, 34-43. [CrossRef] [PubMed]

15. Webb, E.C.; Casey, N.; Simela, L. Goat meat quality. Small Rumin. Res. 2005, 60, 153-166. [CrossRef]

16. Babiker, S.; El Khider, I.; Shafie, S. Chemical composition and quality attributes of goat meat and lamb. Meat Sci. 1990, 28, 273-277. [CrossRef]

17. Chaosap, C.; Sivapirunthep, P.; Takeungwongtrakul, S.; Zulkifli, R.B.M.; Sazili, A.Q.; Chanporn, C.; Panneepa, S.; Sirima, T.; Qurni, S.A. Effects of Zn-L-Selenomethionine on Carcass Composition, Meat Characteristics, Fatty Acid Composition, Glutathione Peroxidase Activity, and Ribonucleotide Content in Broiler Chickens. Food Sci. Anim. Resour. 2020, 40, 338-349. [CrossRef] [PubMed]

18. Chaosap, C.; Sitthigripong, R.; Sivapirunthep, P.; Pungsuk, A.; Adeyemi, K.; Sazili, A.Q. Myosin heavy chain isoforms expression, calpain system and quality characteristics of different muscles in goats. Food Chem. 2020, 321, 126677. [CrossRef]

19. Arthur, J.S.C.; Mykles, D.L. Calpain Zymography with Casein or Fluorescein Isothiocyanate Casein. In Calpain Methods and Protocols; Elce, J.S., Ed.; Humana Press: Totowa, NJ, USA, 2000; pp. 109-116.

20. Khaokhaikaew, S.; Wattanachant, C.; Ngampongsai, W. Effect of Breeds and Rearing Systems of goat on Growth Performance, Carcass Characteristics, Production cost and Economic Return. J. Sci. Technol. Mahasarakham Univ. 2010, $29,32-43$.

21. Hamoen, J.; Vollebregt, H.; van der Sman, R. Prediction of the time evolution of pH in meat. Food Chem. 2013, 141, 2363-2372. [CrossRef]

22. Kadim, I.; Mahgoub, O.; Al-Ajmi, D.; Al-Maqbaly, R.; Al-Saqri, N.; Ritchie, A. An evaluation of the growth, carcass and meat quality characteristics of Omani goat breeds. Meat Sci. 2004, 66, 203-210. [CrossRef]

23. Simela, L.; Webb, E.; Frylinck, L. Effect of sex, age, and pre-slaughter conditioning on $\mathrm{pH}$, temperature, tenderness and colour of indigenous South African goats. S. Afr. J. Anim. Sci. 2004, 34 (Suppl. 1), 208-211.

24. Pophiwa, P.; Webb, E.; Frylinck, L. Carcass and meat quality of Boer and indigenous goats of South Africa under delayed chilling conditions. S. Afr. J. Anim. Sci. 2017, 47, 794. [CrossRef]

25. Casey, N.; Norman, H.; Webb, E.C. Managing goat production for meat quality. Small Rumin. Res. 2010, 89, 218-224. [CrossRef]

26. Carpenter, C.E.; Cornforth, D.P.; Whittier, D. Consumer preferences for beef color and packaging did not affect eating satisfaction. Meat Sci. 2001, 57, 359-363. [CrossRef]

27. King, D.A.; Voges, K.L.; Hale, D.S.; Waldron, D.F.; Taylor, C.A.; Savell, J.W. High voltage electrical stimulation en-hances muscle tenderness, increases aging response, and improves muscle color from cabrito carcasses. Meat Sci. 2004, 68, 529-535. [CrossRef]

28. Trach, N.; Phiovankham, B.; Luc, D. Effects of genotype and nutrition on growth performance, carcass characteristics, and meat properties of goats in Laos. J. South. Agric. 2011, 42, 786-790.

29. Bouton, P.E.; Harris, P.V.; Shorthose, W.R. Effect of ultimate $\mathrm{pH}$ upon the water-holding capacity and tenderness of mutton. $J$. Food Sci. 1971, 36, 435-439. [CrossRef]

30. Shackelford, S.; Morgan, J.; Cross, H.; Savell, J. Identification of Threshold Levels for Warner-Bratzler Shear Force in Beef Top Loin Steaks. J. Muscle Foods 1991, 2, 289-296. [CrossRef]

31. Weston, A.; Rogers, R.; Althen, T. Review: The Role of Collagen in Meat Tenderness. Prof. Anim. Sci. 2002, 18, 107-111. [CrossRef] 
32. Astruc, T. Connective tissue: Structure, function, and influence on meat quality. In Encyclopedia of Meat Sciences; Elsevier: Oxford, UK, 2014; pp. 321-328.

33. Adiwinarti, R.; Kustantinah, B.I.; Rusman, I.E. Improving the performance of local Kacang Goats using ruminally undegradable protein feeds. Asian J. Anim. Sci. 2016, 10, 262-267. [CrossRef]

34. Kannan, G.; Gadiyaram, K.; Galipalli, S.; Carmichael, A.; Kouakou, B.; Pringle, T.; McMillin, K.; Gelaye, S. Meat quality in goats as influenced by dietary protein and energy levels, and postmortem aging. Small Rumin. Res. 2006, 61, 45-52. [CrossRef]

35. Nagaraj, N.S.; Anilakumar, K.; Santhanam, K.S.V. Changes in the Calpain-Calpastatin and Cathepsin (B, B+L, H AND D) during Postmortem Storage of Goat Muscles. J. Food Biochem. 2007, 26, 75-89. [CrossRef]

36. Pringle, T.D.; Williams, S.E.; Lamb, B.S.; Johnson, D.D.; West, R.L. Carcass characteristics, the calpain proteinase system, and aged tenderness of Angus and Brahman crossbred steers. J. Anim. Sci. 1997, 75, 2955-2961. [CrossRef]

37. Ibrahim, R.M.; Goll, D.E.; Marchello, J.A.; Duff, G.C.; Thompson, V.F.; Mares, S.W.; Ahmad, H.A. Effect of two dietary concentrate levels on tenderness, calpain and calpastatin activities, and carcass merit in Waguli and Brahman steers1. J. Anim. Sci. 2008, 86, 1426-1433. [CrossRef] [PubMed]

38. Nakamura, Y.-N.; Tsuneishi, E.; Kamiya, M.; Yamada, A. Histological Contribution of Collagen Architecture to Beef Toughness. J. Food Sci. 2010, 75, E73-E77. [CrossRef] [PubMed]

39. Peña, F.; Bonvillani, A.; Freire, B.; Juárez, M.; Perea, J.; Gómez, G. Effects of genotype and slaughter weight on the meat quality of Criollo Cordobes and Anglonubian kids produced under extensive feeding conditions. Meat Sci. 2009, 83, 417-422. [CrossRef] [PubMed]

40. Pratiwi, N.W.; Murray, P.; Taylor, D. Total cholesterol concentrations of the muscles in castrated Boer goats. Small Rumin. Res. 2006, 64, 77-81. [CrossRef]

41. Beserra, F.; Madruga, M.; Leite, A.; da Silva, E.; Maia, E. Effect of age at slaughter on chemical composition of meat from Moxotó goats and their crosses. Small Rumin. Res. 2004, 55, 177-181. [CrossRef]

42. Pratiwi, N.W.; Murray, P.; Taylor, D.; Zhang, D. Comparison of breed, slaughter weight and castration on fatty acid profiles in the longissimus thoracic muscle from male Boer and Australian feral goats. Small Rumin. Res. 2006, 64, 94-100. [CrossRef]

43. Abdullah, M.M.H.; Jew, S.; Jones, P.J.H. Health benefits and evaluation of healthcare cost savings if oils rich in monounsaturated fatty acids were substituted for conventional dietary oils in the United States. Nutr. Rev. 2017, 75, 163-174. [CrossRef] [PubMed]

44. Banskalieva, V.; Sahlu, T.; Goetsch, A. Fatty acid composition of goat muscles and fat depots: A review. Small Rumin. Res. 2000, 37, 255-268. [CrossRef]

45. Simopoulos, A. The importance of the ratio of omega-6/omega-3 essential fatty acids. Biomed. Pharmacother. 2002, 56, 365-379. [CrossRef]

46. Enser, M.; Richardson, R.; Wood, J.; Gill, B.; Sheard, P. Feeding linseed to increase the n-3 PUFA of pork: Fatty acid composition of muscle, adipose tissue, liver and sausages. Meat Sci. 2000, 55, 201-212. [CrossRef]

47. Rhee, M.-S.; Wheeler, T.; Shackelford, S.; Koohmaraie, M. Variation in palatability and biochemical traits within and among eleven beef muscles. J. Anim. Sci. 2004, 82, 534-550. [CrossRef] [PubMed]

48. Beriain, M.J.; Bas, P.; Purroy, A.; Treacher, T. Effect of Animal and Nutritional Factors and Nutrition on Lamb Meat Quality; CIHEAM: Zaragoza, Spain, 2000; Volume 52.

49. Suzuki, A.; Homma, N.; Fukuda, A.; Hirao, K.; Uryu, T.; Ikeuchi, Y. Effects of high pressure treatment on the flavour-related components in meat. Meat Sci. 1994, 37, 369-379. [CrossRef]

50. Álvarez, C.; Morán, L.; Keenan, D.F.; Mullen, A.-M.; Delgado-Pando, G. Mechanical and Biochemical Methods for Rigor Measurement: Relationship with Eating Quality. J. Food Qual. 2019, 2019, 1894543. [CrossRef]

51. Tikk, M.; Tikk, K.; Tørngren, M.; Meinert, L.; Aaslyng, M.; Karlsson, A.; Andersen, H. Development of Inosine Monophosphate and Its Degradation Products during Aging of Pork of Different Qualities in Relation to Basic Taste and Retronasal Flavor Perception of the Meat. J. Agric. Food Chem. 2006, 54, 7769-7777. [CrossRef] [PubMed] 